\title{
Evaluation Method for Tunneling Stability of TBM Cutterhead
}

\author{
Zhaohui Xu${ }^{1 *}$, Ye Er-ken·Zha Mu-ti², Lin Xue', Fengtao Wang1, Jing Chen³, Junzhou Huo' ${ }^{1}$ \\ ${ }^{1}$ School of Mechanical Engineering, Dalian University of Technology, Dalian, China \\ ${ }^{2}$ Ergis River Basin Development Project Construction Management Bureau, Urumchi, China \\ ${ }^{3}$ School of Navigation and Shipbuilding Engineering, Dalian Ocean University, Dalian, China \\ Email: *1967215814@qq.com
}

How to cite this paper: $\mathrm{Xu}, \mathrm{Z} . \mathrm{H}$., Er-ken-Zha Mu-ti, Y., Xue, L., Wang, F.T., Chen, J. and Huo, J.Z. (2019) Evaluation Method for Tunneling Stability of TBM Cutterhead. World Journal of Engineering and Technology, 7, 1-9.

https://doi.org/10.4236/wjet.2019.72B001

Received: January 14, 2019

Accepted: May 14, 2019

Published: May 17, 2019

\begin{abstract}
In the process of tunneling of tunnel boring machine (TBM), different geological conditions often correspond to different working conditions, and the randomness of geological conditions also causes the order of occurrence of each working condition to be different. Under the conversion of different working conditions, this makes the vibration of different types of cutterheads different. How to choose the appropriate type of cutterhead according to different geological conditions is very important for saving engineering cost and increasing cutterhead life. In view of the above situation, this paper proposes a stability evaluation method during the TBM tunneling process to select the appropriate cutterhead type. Firstly, the corresponding relationship between geology and working conditions is established according to different geological conditions, and the input loads corresponding to geological conditions are obtained. Then, it is substituted into the dynamic model of the cutterhead system, the vibration response boundaries of each degree of freedom are obtained by solving. And the average value of the maximum boundary amplitude of each degree of freedom is taken to represent the extreme vibration of the cutterhead under the corresponding working conditions. Finally, by comparing the fluctuation of the ultimate vibration amplitude of each type of cutterhead in the process of working condition conversion, the results are as follows: when the transition between homogeneous strata and composite strata is normal and there is no large turning and deviation correction, the vibration response of the two-part cutterhead is the smallest, and the two-part cutterhead is the best choice. Otherwise, the five-part cutterhead is the best choice, while the stability of the integrated cutterhead is the worst.
\end{abstract}

\section{Keywords}

Cutterhead, Working Condition Conversion, Stability, Type Selection of Cutterhead 


\section{Introduction}

Mechanised tunneling is an efficient tunneling technology for the construction fnew underground infrastructures, in particular in urban environments [1]. Tunnel boring machine (TBM) is a factory-built tunnel construction system integrating mechanical, electrical, hydraulic and other multidisciplinary applications. It is widely used in underground projects such as water conservancy, transportation, national defense and energy. Cutterhead system is the most critical component, its engineering failure will greatly affect the progress of the project, increase time and money costs. Cutterhead system tunneling process is often different because of different geological conditions. How to carry out dynamic analysis more effectively and accurately is of great significance for studying the tunneling stability of the cutterhead system and selecting the type of cutterhead.

At present, scholars have done a lot of research on the dynamic characteristics of the key parts of TBM. Zhou et al. [2] proposed and established an equivalent coupling model through the secondary development of the finite element software ABAQUS, and carried out the corresponding dynamic analysis. Huoet al. [3] established a multi-degree-of-freedom coupling dynamic model of TBM, and studied the dynamic response of cutterhead under impact load. Li et al. [4] established a general nonlinear time-varying (NLTV) dynamic model and a linear time-varying (LTV) dynamic model for the shield tunneling machine drive system, and the effects of physical parameters under various conditions of dynamic model are analyzed. Zhang, Li et al. [5] [6] established a dynamic model of shield machine under complex geological conditions, calculated the dynamic response of the cutterhead slewing system, and explored the influence of key parameters. Cooley and Parker [7] studied the effect of the speed of the planetary carrier on the natural frequency of the system. Han [8] introduced a nonlinear spring element to simulate the interaction between the cutterhead and the rock, and established a finite element model to simulate the dynamic process of the tunneling process.

In conclusion, although scholars have done a lot of research on the key parts of TBM, most of the dynamic analysis of TBM has not considered the influence of geological conditions, and few studies have been carried out on geological transformation and cutterhead selection. In view of the above problems, this paper presents a stability evaluation method in TBM tunneling process. Firstly, the corresponding relationship between geology and working conditions is established according to different geological conditions, and the input loads corresponding to geological conditions are obtained. Then, it is substituted into the dynamic model of the cutterhead system, the vibration response boundaries of each degree of freedom are obtained by solving. And the average value of the maximum boundary amplitude of each degree of freedom is taken to represent the extreme vibration of the cutterhead under the corresponding working conditions. Finally, by comparing the fluctuation of the ultimate vibration amplitude 
of each type of cutterhead in the process of working condition conversion, the stability of each type of cutterhead under different geological conditions is obtained.

\section{Transformation of Geological and Working Conditions}

According to the statistics of engineering geology, the location of TBM contains many strata in the process of tunneling, and the distribution characteristics of strata are uncertain. According to the research of relevant scholars, the changing trend of strata on the cutterhead tunneling interface and the distribution and combination of different geology have great influence on the fluctuation and magnitude of cutter head load. Therefore, it is necessary to deal with the stratigraphic distribution. This article uses classical working conditions to equate possible geological forms. The working conditions that may occur during the tunneling process are attributed to the maximum thrust condition, the maximum overturning condition, the turning and correcting condition and out of difficult condition. The typical working conditions are shown in Figure 1. The maximum thrust condition refers to the equivalent condition of TBM driving along a straight line under uniform geology. At this time, all the cutters are subjected to rock breaking load, and the cutterhead system bears the maximum load, and its force section is shown in Figure 1(a); Maximum overturning condition refers to the equivalent condition of TBM driving in composite strata. At this time, half of the cutter of the cutterhead contacts the rock, and the cutterhead system bears large loads and bending moments, and its force section is shown in Figure 1(b); The turning and correcting condition means that there is a certain angle between the cutterhead surface and the tunneling surface, only part of the cutter is subjected to force, and its force section is shown in Figure $\mathbf{1}$ (c). When TBM is driving, it may encounter problems such as the lone stone or the edge cutter being stuck. At this time, the cutterhead torque must be increased. The cutter head is subjected to the maximum torque under this condition, and its force section is shown in Figure 1(d).

Considering the corresponding relationship between the geological distribution and the working conditions, the calculation process of the cutterhead load boundary is as follows.

1) Combining simulation and field test data to obtain the load waveform of a single cutter;

2) According to the geological survey report, the geological conditions are statistically analyzed and classified, and several typical working conditions with the largest proportion are found;

3) According to the obtained working conditions and the load waveform of the single cutter, the time history of the equivalent load of the cutterhead under working conditions with the largest proportion is fitted, and the minimum value of the cutterhead load is obtained.

4) The maximum value of the cutterhead load is generated when the load on each cutter is nominal. Therefore, the load interval of the cutterhead under 


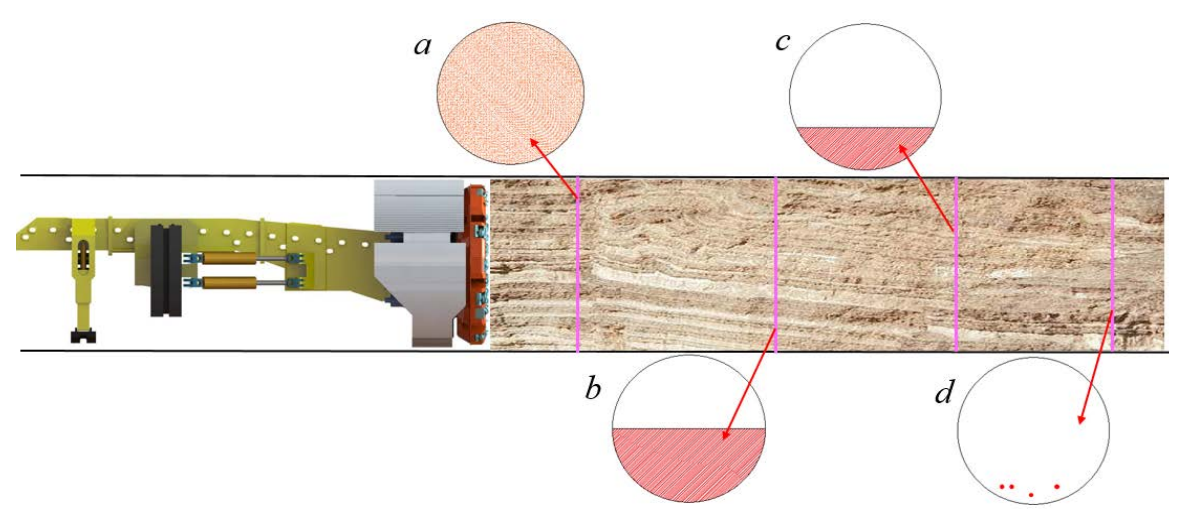

Figure 1. Transformation of geology and working conditions.

several typical working conditions with the largest proportion can be obtained and used as the load input of the dynamic model.

\section{Establishment of Dynamic Model}

\subsection{Equivalent of Mechanical Model}

The TBM cutterhead system includes cutterhead, ring gear, pinion, shield, reducer and motor. The typical cutterhead forms are integrated cutterhead (IC), two-part cutterhead (TPC), and five-part cutterhead (FPC). The cutterhead, ring gear, pinion, shield and motor are equivalent to mass points, and the pinion and red tarder are equivalent to a mass point. The equivalent mechanical model of cutterhead is established, as shown in Figure 2.

$m_{\delta}(\delta=L, r, d, p j)$ represents the equivalent mass of cutterhead, ring gear, shield and pinion, respectively. $k_{e q \delta}(\delta=x, y, L, r, z, d, d z, p)$ represents horizontal equivalent support stiffness of cutterhead, longitudinal equivalent support stiffness of cutterhead, radial equivalent support stiffness of ring gear, axial equivalent support stiffness of ring gear, horizontal equivalent support stiffness longitudinal equivalent support stiffness and axial equivalent support stiffness of shield, and the equivalent support stiffness of the pinion respectively. $C_{\text {eq } \delta} \delta=x$, $y, L, r, z, d, d z, p$ ) represents horizontal damping coefficient of cutterhead, longitudinal damping coefficient of cutterhead, radial damping coefficient of ring gear, axial damping coefficient of ring gear, horizontal damping coefficient, longitudinal damping coefficient and axial damping coefficient of shield, and the damping coefficient of the pinion respectively. $T_{L}, T_{m p} F_{X P} F_{Y}, M_{X}, M_{Y}, F_{L}$ represents cutterhead torque, motor torque, cutterhead horizontal load, cutterhead longitudinal load, cutterhead overturning moment, cutterhead axial load.

According to the equivalent mechanical model, the generalized displacement matrix of the cutter head system is:

$$
\begin{aligned}
\{\delta\}=\{ & X_{L}, Y_{L}, Z_{L}, \theta_{L x}, \theta_{L y}, \theta_{L}, X_{r}, Y_{r}, \\
& \left.Z_{r}, \theta_{x}, \theta_{y}, \theta_{r}, X_{d}, Y_{d}, Z_{d}, H_{p j}, V_{p j}, \theta_{p j}, \theta_{m j}\right\}^{T} \quad(\mathrm{j}=1 \text { - pinion number) (1) }
\end{aligned}
$$

In the matrix, $X_{L}, Y_{L}, Z_{L}, \theta_{L x} \theta_{L y} \theta_{L}$ represents the X-direction displacement of the cutterhead, the Y-direction displacement of the cutterhead, the axial 


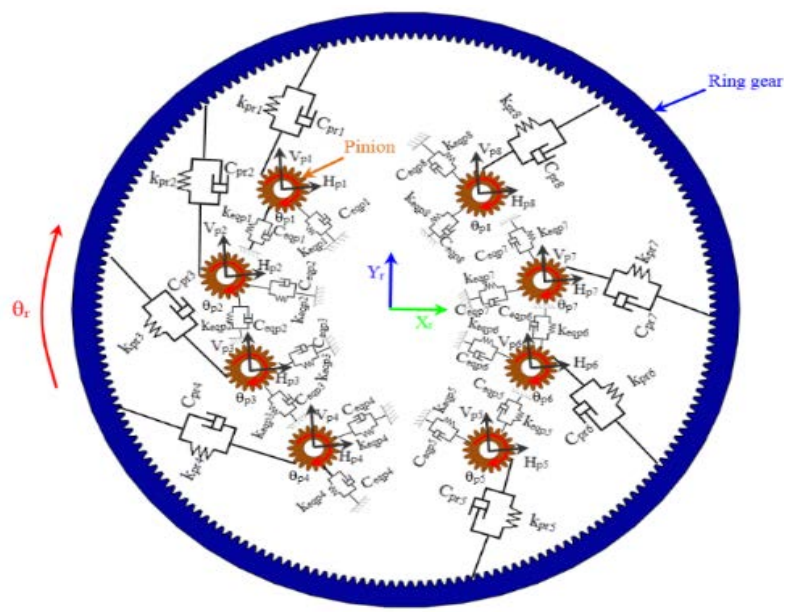

(a)

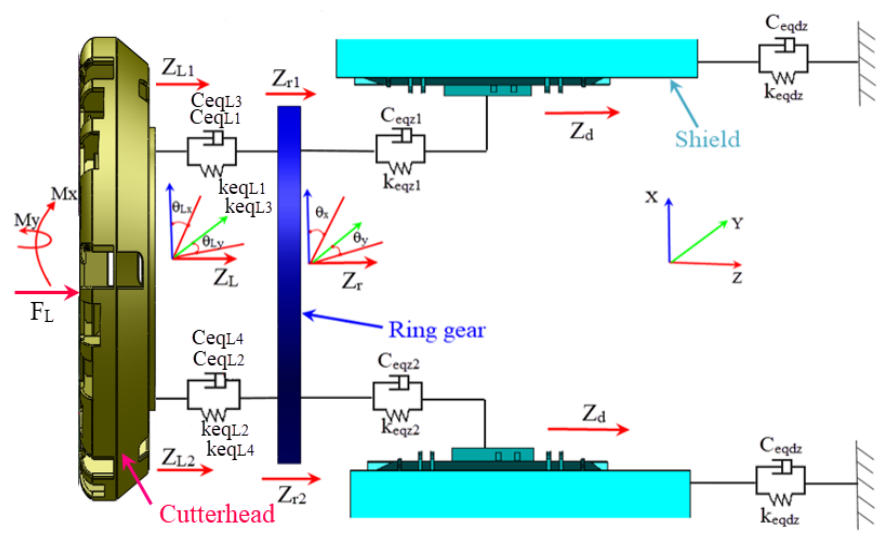

(c)

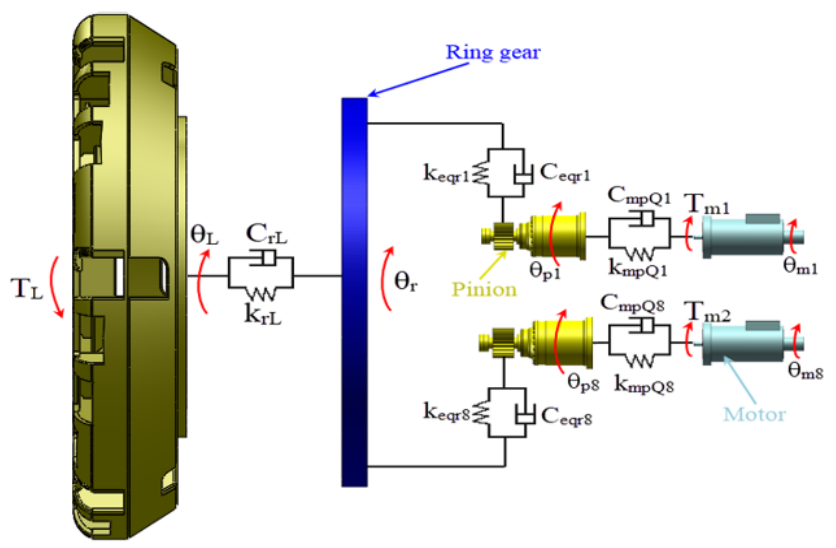

(b)

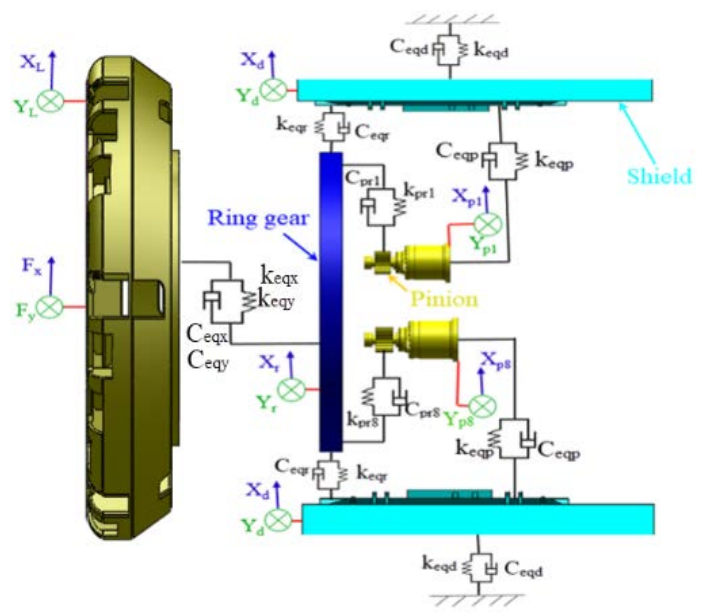

(d)

Figure 2. Equivalent mechanical model of cutterhead. (a) Mechanics Model of Rotary System; (b) Torsional Mechanics Model; (c) Mechanical Model of Axis and Overturning; (d) Radial Mechanics Model.

displacement of the cutterhead, the overturning vibration displacement of the cutterhead, and the torsional vibration displacement of the cutterhead respectively; $X_{r}, Y_{r}, Z_{r}, \theta_{x}, \theta_{y}, \theta_{r}$ represents the X-direction displacement of the ring gear, the $\mathrm{Y}$-direction displacement of the ring gear, the axial displacement of the ring gear, the overturning vibration displacement of the ring gear, and the torsional vibration displacement of the ring gear respectively; $X_{\phi} Y_{\phi} Z_{d}$ represents the $\mathrm{X}$-direction displacement of the shield, the Y-direction displacement of the shield, the axial displacement of the shield respectively; $H_{p \gg} \quad V_{p p} \theta_{p j}$ represents tangential displacement of pinion, radial displacement of pinion, the torsional vibration displacement of pinion respectively; $\theta_{m j}$ represent angular displacement of torsional vibration of motor.

\subsection{Establishment of Dynamics Differential Equation of Cutterhead System}

According to the dynamic equivalent model of the cutterhead and the transfor- 
mation relationship between geology and working conditions, the corresponding dynamic differential equations are obtained.

1) Cutterhead

$$
\left\{\begin{array}{l}
m_{L} \ddot{X}_{L}+C_{e q x}\left(\dot{X}_{L}-\dot{X}_{r}\right)+k_{e q x}\left(X_{L}-X_{r}\right)=F_{X}^{I} \\
m_{L} \ddot{Y}_{L}+C_{e q y}\left(\dot{Y}_{L}-\dot{Y}_{r}\right)+k_{e q y}\left(Y_{L}-Y_{r}\right)=F_{Y}^{I} \\
m_{L} \ddot{Z}_{L}+\sum_{i=1}^{4}\left[C_{e q L i}\left(\dot{Z}_{L i}-\dot{Z}_{r i}\right)+k_{e q L i}\left(Z_{L i}-Z_{r i}\right)\right]=F_{L}^{I} \\
I_{L x} \ddot{\theta}_{L x}+r_{b r}\left[C_{e q L 1}\left(\dot{Z}_{L 1}-\dot{Z}_{r 1}\right)-C_{e q L 3}\left(\dot{Z}_{L 3}-\dot{Z}_{r 3}\right)+k_{e q L 1}\left(Z_{L 1}-Z_{r 1}\right)\right. \\
\left.\quad-k_{e q L 3}\left(Z_{L 3}-Z_{r 3}\right)\right]=M_{X}^{I} \\
I_{L y} \ddot{\theta}_{L y}+r_{b r}\left[C_{e q L 2}\left(\dot{Z}_{L 2}-\dot{Z}_{r 2}\right)-C_{e q L 4}\left(\dot{Z}_{L 4}-\dot{Z}_{r 4}\right)+k_{e q L 2}\left(Z_{L 2}-Z_{r 2}\right)\right. \\
\left.\quad-k_{e q L 4}\left(Z_{L 4}-Z_{r 4}\right)\right]=M_{Y}^{I} \\
\ddot{I}_{L}+C_{r L Q}\left(\dot{\theta}_{L}-\dot{\theta}_{r}\right)+k_{r L Q}\left(\theta_{L}-\theta_{r}\right)=-T_{L}^{I}
\end{array}\right.
$$

2) Ring gear

$$
\left\{\begin{array}{l}
m_{r} \ddot{X}_{r}+\sum_{j=1}^{n}\left(F_{p r j}+D_{p r j}\right) \sin \left(\varphi_{j}+\alpha\right)+C_{e q p r}\left(\dot{X}_{r}-\dot{X}_{d}\right)+C_{e q x}\left(\dot{X}_{r}-\dot{X}_{L}\right) \\
+k_{e q r}\left(X_{r}-X_{d}\right)+k_{e q x}\left(X_{r}-X_{L}\right)=0 \\
m_{r} \ddot{Y}_{r}-\sum_{j=1}^{n}\left(F_{p r j}+D_{p r j}\right) \cos \left(\varphi_{j}+\alpha\right)+C_{e q r}\left(\dot{Y}_{r}-\dot{Y}_{d}\right)+C_{e q y}\left(\dot{Y}_{r}-\dot{Y}_{L}\right) \\
+k_{e q r}\left(Y_{r}-Y_{d}\right)+k_{e q y}\left(Y_{r}-Y_{L}\right)=0 \\
m_{r} \ddot{Z}_{r}+\sum_{i=1}^{4}\left[C_{e q L i}\left(\dot{Z}_{r i}-\dot{Z}_{L i}\right)+C_{e q z i}\left(\dot{Z}_{r i}-\dot{Z}_{d}\right)+k_{e q L i}\left(Z_{r i}-Z_{L i}\right)+k_{e q z i}\left(Z_{r i}-Z_{d}\right)\right]=0 \\
I_{r x} \ddot{\theta}_{x}+r_{b r}\left[C_{e q L 1}\left(\dot{Z}_{r 1}-\dot{Z}_{L 1}\right)-C_{e q L 3}\left(\dot{Z}_{r 3}-\dot{Z}_{L 3}\right)+C_{e q z 1}\left(\dot{Z}_{r 1}-\dot{Z}_{d}\right)-C_{e q z 3}\left(\dot{Z}_{r 3}-\dot{Z}_{d}\right)\right] \\
+r_{b r}\left[k_{e q L 1}\left(Z_{r 1}-Z_{L 1}\right)-k_{e q L 3}\left(Z_{r 3}-Z_{L 3}\right)+k_{e q z 1}\left(Z_{r 1}-Z_{d}\right)-k_{e q z 3}\left(Z_{r 3}-Z_{d}\right)\right]=0 \\
I_{r y} \ddot{\theta}_{y}+r_{b r}\left[C_{e q L 2}\left(\dot{Z}_{r 2}-\dot{Z}_{L 2}\right)-C_{e q L 4}\left(\dot{Z}_{r 4}-\dot{Z}_{L 4}\right)+C_{e q z 2}\left(\dot{Z}_{r 2}-\dot{Z}_{d}\right)-C_{e q z 4}\left(\dot{Z}_{r 4}-\dot{Z}_{d}\right)\right] \\
+r_{b r}\left[k_{e q L 2}\left(Z_{r 2}-Z_{L 2}\right)-k_{e q L 4}\left(Z_{r 4}-Z_{L 4}\right)+k_{e q z 2}\left(Z_{r 2}-Z_{d}\right)-k_{e q z 4}\left(Z_{r 4}-Z_{d}\right)\right]=0 \\
I_{r} \ddot{\theta}_{r}-\sum_{j=1}^{n}\left(F_{p r j}+D_{p r j}\right) r_{b r}+C_{r L Q}\left(\dot{\theta}_{r}-\dot{\theta}_{L}\right)+k_{r L Q}\left(\theta_{r}-\theta_{L}\right)=0
\end{array}\right.
$$

3) Shield

$$
\left\{\begin{array}{l}
m_{d} \ddot{X}_{d}+C_{e q r}\left(\dot{X}_{d}-\dot{X}_{r}\right)+C_{e q d} \dot{X}_{d}+k_{e q r}\left(X_{d}-X_{r}\right)+k_{e q d} X_{d}=0 \\
m_{d} \ddot{Y}_{d}+C_{e q r}\left(\dot{Y}_{d}-\dot{Y}_{r}\right)+C_{e q d} \dot{Y}_{d}+k_{e q r}\left(Y_{d}-Y_{r}\right)+k_{e q d} Y_{d}=0 \\
m_{d} \ddot{Z}_{d}+\sum_{i=1}^{4}\left[C_{e q z i}\left(\dot{Z}_{d}-\dot{Z}_{r i}\right)+k_{e q z i}\left(Z_{d}-Z_{r i}\right)\right]+C_{e q d z} \dot{Z}_{d}+k_{e q d z} Z_{d}=0
\end{array}\right.
$$

4) Pinion

$$
\left\{\begin{array}{l}
m_{p j} \ddot{H}_{p j}+\left(F_{p r j}+D_{p r j}\right) \cos \alpha+C_{e q p j} \dot{H}_{p j}+k_{e q p j} H_{p j}=0 \\
m_{p j} \ddot{V}_{p j}+\left(F_{p r j}+D_{p r j}\right) \sin \alpha+C_{e q p j} \dot{V}_{p j}+k_{e q p j} V_{p j}=0 \\
I_{p j} \ddot{\theta}_{p j}+\left(F_{p r j}+D_{p r j}\right) r_{b p}+C_{m p Q}\left(\dot{\theta}_{p j}-\dot{\theta}_{m j}\right)+k_{m p Q}\left(\theta_{p j}-\theta_{m j}\right)=0
\end{array}\right.
$$

5) Motor

$$
I_{m j} \ddot{\theta}_{m j}+C_{m p Q}\left(\dot{\theta}_{m j}-\dot{\theta}_{p j}\right)+k_{m p Q}\left(\theta_{m j}-\theta_{p j}\right)=T_{m j}
$$

\section{Result Analysis}

\subsection{Data Statistics}

According to the different working conditions under different geological condi- 
tions, this paper establishes the relationship between geological and working conditions, obtains the load corresponding to the geology, and substitutes it into the dynamic model of the cutterhead system. The vibration response boundaries of each degree of freedom of the cutter head are obtained by solving the dynamic model. The maximum response intervals of the degree of freedom of the IC, the TPC and the FPC under different working conditions are counted. This paper takes the integrated cutter head as an example, as shown in Table 1.

\subsection{Analysis of the Conversion Process of Cutterhead}

Firstly, the upper boundaries of the respective degrees of freedom under the various working conditions of the cutterheadare separately summed. Then the average of the upper boundaries of the respective degrees of freedom response boundary is used to represent the response of each cutterhead under various working conditions. Finally, the condition transformation analysis is carried out to obtain the cutterhead stability and cutterhead selection under different geological conditions. In this paper, the first cut-off time is from the beginning of tunneling to the first entry into the Out of difficult condition. The comparative analysis of the conversion differences between different working conditions of different cutterheads are shown in Figure 3.

a) Working conditions conversion(Maximum thrust condition/Maximum overturning condition/Turning and correcting condition/Out of difficult condition); b) Working conditions conversion (Maximum thrust condition/Turning and correcting condition/Maximum overturning condition/Out of difficult condition); c) Working conditions conversion (Maximum overturning condition/Maximum thrust condition/Turning and correcting condition/Out of difficult condition); d) Working conditions conversion (Maximum overturning condition/Turning and correcting condition/Maximum thrust condition/Out of difficult condition).

Through engineering experience, during the normal excavation of the cutterhead, the most common working conditions of the cutterhead are the maximum thrust condition and the maximum overturning condition. Since the geological transformation process corresponds to different vibration conditions, the fluctuation of the vibration difference in different geological transformations can be

Table 1. Statistics on the maximum response boundary of the IC.

\begin{tabular}{cccccc}
\hline & $\begin{array}{c}\text { The maximum } \\
\text { overturning condition }\end{array}$ & $\begin{array}{c}\text { The maximum } \\
\text { thrust condition }\end{array}$ & $\begin{array}{c}\text { The turning and } \\
\text { correcting condition }\end{array}$ & $\begin{array}{c}\text { Out of difficult } \\
\text { condition }\end{array}$ \\
\hline 1 & {$[-0.0039,0.0038]$} & {$[-0.0020,0.0024]$} & {$[-0.0017,0.0019]$} & {$[-0.0013,0.0016]$} \\
2 & {$[-0.0022,0.0022]$} & {$[-0.0018,0.0019]$} & {$[-0.0015,0.0016]$} & {$[-0.0012,0.0014]$} \\
3 & {$[-0.0004,0.0013]$} & {$[-0.0036,0.0044]$} & {$[-0.0005,0.0006]$} & {$[-0.0001,0.0001]$} \\
4 & {$[-0.0030,0.0030]$} & {$[-0.0003,0.0004]$} & {$[-0.0002,0.0002]$} & {$[-0.0001,0.0001]$} \\
5 & {$[-0.0021,0.0021]$} & {$[-0.0001,0.0001]$} & {$[-0.0007,0.0009]$} & {$[-0.0001,0.0002]$} \\
6 & {$[0,0.0004]$} & {$[0,0.0005]$} & {$[0,0.0006]$} & {$[0,0.0006]$} \\
\hline
\end{tabular}



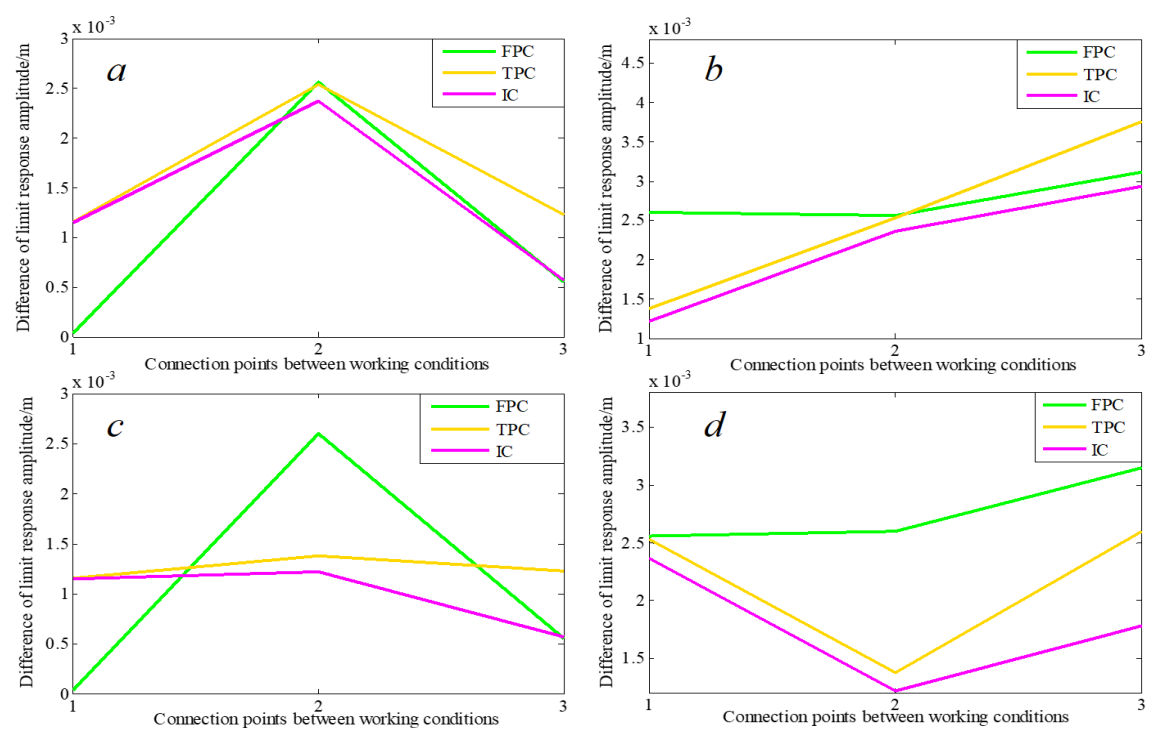

Figure 3. Working conditions conversion of different cutterheads.

reflected in the stability of different types of cutterheads during geological conditions conversion. Through the analysis of the transformation process of different working conditions and the analysis of the correspondence between geology and working conditions, we can draw the following conclusions: When the maximum thrust condition and the maximum overturning condition are normal transition (for example, the transition without turning and correcting), that is, the normal transition between the uniform rock stratum and the composite rock stratum, the vibration response of the TPC is the smallest, its working condition transition is the smoothest. In this case, the TPC is preferred. (2) When the maximum thrust condition and the maximum overturning condition are abnormal transitions, the vibration response of the FPC is the smallest, its working condition transition is the smoothest. In this case, the FPC is preferred.

\section{Acknowledgements}

This work is supported by the National Natural Science Foundation of China (Grant No. 51875076), NSFC-Liaoning United Key fund (Grant No. U1708255).

\section{Conflicts of Interest}

The authors declare no conflicts of interest regarding the publication of this paper.

\section{References}

[1] Freitag, S., Cao, B.T., Ninić, J., et al. (2017) Recurrent Neural Networks and Proper Orthogonal Decomposition with Interval Data for Real-Time Predictions of Mechanised Tunneling Processes. Computers \& Structures. https://doi.org/10.1016/j.compstruc.2017.03.020

[2] Zhou, Y., Kai, S. and Wu, H.G. (2016) Dynamic Evolution Mechanism of Seepage in Deep-Buried TBM Tunnel. Journal of Central South University. 
[3] Huo, J., Wu, H., Sun, W., et al. (2017) Electromechanical Coupling Dynamics of TBM Main Drive System. Nonlinear Dynamics, No. 2, 1-24.

[4] Li, X.H., et al. (2013) Research on Dynamic Models and Performances of Shield Tunnel Boring Machine Cutterhead Driving System. Advances in Mechanical Engineering, 29. https://doi.org/10.1155/2013/359757

[5] Cooley, C.G. and Parker, R.G. (2012) Vibration Properties of High-Speed Planetary Gears with Gyroscopic Effects. Journal of Vibration and Acoustics, 134, Article ID: 061014. https://doi.org/10.1115/1.4006646

[6] Zhang, K., Yu, H., Liu, Z., et al. (2010) Dynamic Characteristic Analysis of TBM Tunneling in Mixed-Face Conditions. Simulation Modelling Practice \& Theory, 18, 1019-1031. https://doi.org/10.1016/j.simpat.2010.03.005

[7] Xian, H.L., Hai, B.Y., Ming, Z.Y., et al. (2010) Dynamic Modeling and Analysis of Shield TBM Cutterhead Driving System. Journal of Dynamic Systems Measurement and Control, 132, 1-14. https://doi.org/10.1115/1.4000818

[8] Han, M., Cai, Z. and Qu, C. (2014) Study on the Critical Driving Speed of the Tunnel Boring Machine Cutterhead Based on the Dynamic Stability. Journal of Mechanical Engineering, 50, 10-16. https://doi.org/10.3901/JME.2014.21.010 